\title{
New taxonomical and biological observations on Jujubinus seguenzae Ghisotti et Melone, 1975 (Gastropoda Vetigas- tropoda Trochidae)
}

\author{
Danilo Scuderi ${ }^{*}$, Alberto Villari² \& Alfio Viola' \\ ${ }^{1}$ I.I.S.S. “E. Majorana”, via L. Capuana 36, 95048 Scordia, Italy; e-mail: danscu@tin.it \\ ${ }^{2}$ Via Villa Contino 30, 98124 Messina, Italy; e-mail: villaria@tiscali.it \\ ${ }^{3}$ Dipartimento di Scienze Biologiche, Geologiche ed Ambientali, Sezione di Scienze della Terra, Palazzo Ramondetta, \\ Corso Italia 57, Catania, Italy; e-mail: aviola@unict.it
}

ABSTRACT

KEY WORDS

\begin{abstract}
The study of numerous shells in the collection of the Authors and the finding of new material, among which a single living specimen, some kilometers South to the known geographical area of distribution, allowed us a better accurate morphological study of the shell, the protoconch shape and sculpture and the anatomy and color pattern of the external soft parts. Thus new data allowed to enlarge its geographical distribution and the current taxonomical status of the species. Comparisons with shell and soft parts of similar congeners are made. In particular, differences between Jujubinus seguenzae Ghisotti et Melone, 1975 and the main "morphs" of J. striatus (Linnaeus, 1758) (Gastropoda Vetigastropoda Trochidae) will be underlined and the possibility that this last taxon would be better re-defined on the basis of the original materials is discussed.
\end{abstract}

Jujubinus seguenzae complex; Trochidae; Recent; Mediterranean Sea; living animal.

Received 10.07.2018; accepted 12.09.2018; published online 20.12.2019

Proceedings of the 4th International Congress on Biodiversity "Man, Natural Habitats and Euro-Mediterranean Biodiversity", November 17th-19th, 2017 - Malta

\section{INTRODUCTION}

The family Trochidae, top-snails or top-shells, have recently received a lot of attention, especially representatives of the genus Jujubinus Monterosato, 1884. A recently updated checklist for Trochidae listed 18 extant species of this genus present in the Mediterranean Sea. It is still unclear whether some of these species should be considered subspecies. Among these latter species we can consider J. seguenzae Ghisotti et Melone, 1975, known for the shallow waters of the Strait of Messina, although living specimens were never till now documented.
This species is currently considered a nomen dubium (WoRMS citing Oliverio, 2006 as a font). This is probably due to the lack of biological informations and its morphological resemblance with $J$. striatus (Linnaeus, 1758), to which Ghisotti \& Melone (1975) connected it. No papers had never really discussed its taxonomical position, except for the paper of Cretella (1993), who proposed a good schematic re-description of the species, so considering it as valid.

The exam of photographs of the type material of $J$. striatus in the Linnean collection convinced us that it is constituted by more than one species, but no one attributable to J. seguenzae. It probably rep- 
resents a complex of species, some of which were described as new in recent time, i.e. J. curinii Bogi et Campani, 2006, J. trilloi and J. eleonorae Smriglio, Di Giulio et Mariottini, 2014, J. alboranensis Smriglio, Mariottini et Oliverio, 2015, while others still continue to have an uncertain taxonomical position, i.e. J. fraterculus (Monterosato, 1879), considered as valid by Scuderi \& Terlizzi (2012), or J. striatus delpreteanus Sulliotti, 1889, which was never formally collected and treated in recent time.

The aim of the present paper after new recent findings is to well characterise the taxonomical position of $J$. seguenzae, resolving the question whether it could be considered a good species. In addition, we trace again its distributional geographic area and we give some new morphological informations, among which the resemblance of the external soft parts, for which the features and colour of snout lappets and of the sense organs at the base of the pedal tentacles are here reported as taxonomically discriminant.

\section{MATERIAL AND METHODS}

Morphological studies were conducted on the dry materials of the "J. striatus complex" species of our own collections: complete data are reported under in the examined material. Specimens were counted and measured. Live collected specimens were obtained by brushing small stones covered by green algae in shallow waters and sampling on the leaf stratum the vagile fauna using the handtowed net method by a $40 \times 20 \mathrm{~cm}$ hand-towed net with a $0.5 \mathrm{~mm}$ mesh. Drawings of the external soft parts were made for comparisons to similar congeners. For the evaluation of the shape and the sculpture of the protoconch SEM photographs of the studied taxa were made.

ACRONYMS AND ABBREVIATIONS. AVC: Alberto Villari collection, Messina, Italy; DSC: Danilo Scuderi collection, Catania, Italy; sh/s.: empty shells; sp.: living collected specimen/s.

\section{RESULTS}

\section{Systematics}

Classis GASTROPODA Cuvier, 1795

Subclassis VETIGASTROPODA Salvini-Plawen, 1980

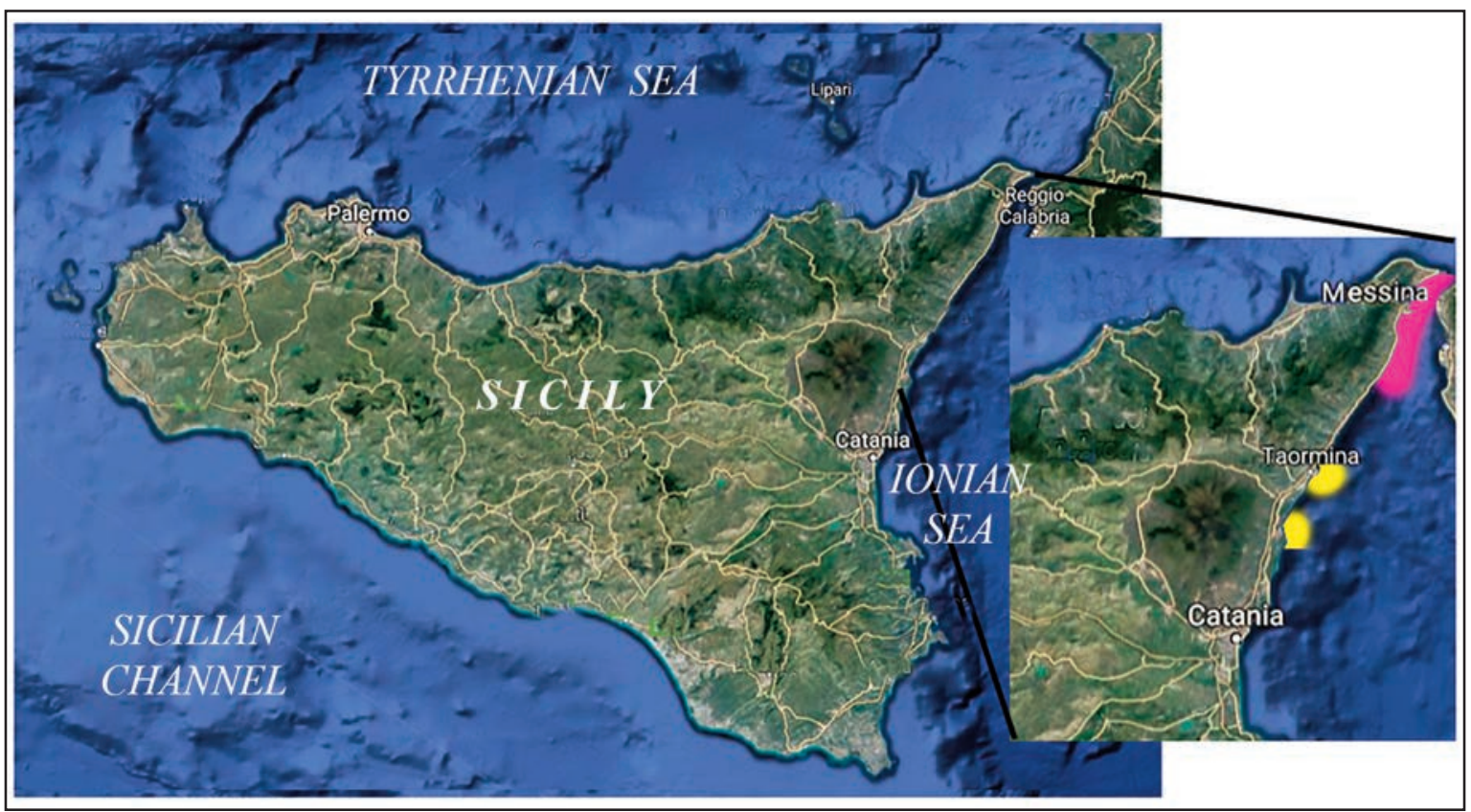

Figure 1. Map of the distribution of Jujubinus seguenzae in eastern Sicily: pink colored area represents the distribution of the species according to literature data, confirmed by material seen by the authors; yellow colored areas show the new findings out of the Strait of Messina. 
Ordo TROCHIDA Rafinesque, 1815

SuperfamiliaTROCHOIDEA Rafinesque, 1815

Familia TROCHIDAE Rafinesque, 1815

Subfamilia TROCHINAE Rafinesque, 1815

Genus Jujubinus Monterosato, 1884

TYPE SPECIES. Trochus matonii Payraudeau, $1826=$ Jujubinus exasperatus (Pennant, 1777) by subsequent designation.

Jujubinus seguenzae Ghisotti et Melone, 1975

EXAMINED MATERIAL. Italy. Ganzirri, Messina, N-E Sicily, 18 sh., shell grit collected at $-2 / 4 \mathrm{~m}$ and beached (DSC). Riviera Paradiso, Messina, N-E Sicily, 20 sp., on floating algae of the genus Ulva (AVC). Riviera Paradiso, Messina, N-E Sicily, 35 sp., on the sea-grass Posidonia oceanica (AVC). San Raineri, "Degassifica" station, Messina, N-E Sicily, 4 sp., shell grit collected at $-4 / 8$ m (AVC). Furci Siculo, Messina N-E Sicily, 2 sp., on rocks with a thin algal film (AVC). Giardini Naxos, Messina, E Sicily, 1 sh., beached (DSC). Riposto, Catania, E Sicily, $-6 / 20 \mathrm{~m}, 19$ sh. collected by a 20 litres grab and $1 \mathrm{sp}$. brushing handily little stones covered by green algae (DSC).

Jujubinus depictus. Italy. Taormina, Messina, N-E Sicily, 23 sh. on rocks, -4/6 m (AVC). Ganzirri, Messina, N-E Sicily, 33 sh., shell grit collected at 2/4 m (AVC). San Giovanni Li Cuti/Cajto, Catania, E Sicily, $311 \mathrm{sh}$. and $25 \mathrm{sp}$., shell grit collected at $2 / 22 \mathrm{~m}$ and fishing nets (DSC).

Jujubinus striatus. Italy. Acitrezza, Catania, E Sicily, 22 sh., fishing nets, -10/20 m (AVC). Riviera Paradiso, Messina, N-E Sicily, 76 sh. on Posidonia oceanica, -4/8 m (AVC). Taormina, Messina, N-E Sicily, 43 sh. on Posidonia oceanica, $-4 / 10 \mathrm{~m}$ (AVC). Brucoli, Siracusa, S-E Sicily, 38 sp., beached shell grit (DSC). Marzamemi, Siracusa, SE Sicily, 18 sp., hand-towed net method on Posidonia oceanica, -4/6 m (DSC).

Jujubinus striatus delpreteanus. Italy. Lago Faro, Messina, N-E Sicily, 135 sh., shell grit collected at $-1 / 2 \mathrm{~m}$ (AVC/DSC).

Jujubinus exasperatus. Italy. Terrauzza, Siracusa, S-E Sicily, 1 sp., hand-towed net method on Posidonia oceanica, 4/6 m (DSC).

Jujubinus tumidulus. Italy. Ganzirri, Messina, N-E Sicily, 41 sh., shell grit collected at $-100 / 120$ $\mathrm{m}$ by fishing nets (AVC/DSC).
Description. Shell. We refer to the good description of Cretella (1993) for the general shape, dimensions, colour and sculpture of the teleoconch, which is well characterized by a more conic shell in comparison to that of the other congeners. Further diagnostic characters on the teleoconch, protoconch and external soft parts and comparisons are here added.

Teleoconch: general shape is an almost high regular cone (Figs. 2-6), with up to 5.5 flat whorls, the first of which is characteristically dome-shaped. Protoconch and initial teleoconch whorls are of the same colour of the rest of the shell. Whorls are sculptured by $5-8$ almost flat and smooth spiral ridges, larger than interspaces, which sometimes could be divided each in two smaller cordlets; dense prosocline growth lines between interspaces and over the spirals. The two adsutural and absutural are well marked, closer and sometimes incised by growth lines, which could form not well marked granulations (Fig. 7).

The base is slightly convex to almost flat, without umbilicus. Peristome squared, only slightly rounded in some specimens at the lower external corner. The columellar wall is straight until $1 / 3$ down of its length, where a not marked columellar fold is present. Colour gray-yellowish, with white and brownish alternated and opisthocline large flames, which in the spiral ridges appear as small alternated dots. Dark-gray and yellowish specimens with small alternated dots are not uncommon (Fig. $5)$.

Protoconch constituted by 1 flat whorl, almost at the same plan of the tele-whorls (Figs. 8, 9). Sculpture is formed by little but numerous and scattered granules of irregular shape, which merge in two faint spiral treads, one in the middle and one uppermost.

External soft parts (Fig. 23): general feature as in Jujubinus species. Foot well developed, granulose on the surface, cream in ground colour, with brown small dashes and big spots arranged in two main rows and one of smaller spots, alternated to white one, along the epipodial ridge, which bears a wide and pointed denticulated margin; numerous expansions at the lower margin; white tail of the foot; two long and tapered cephalic tentacles with dentate sides and thin dark little lines and small white dots along the entire length; three couples of epipodial tentacles similar in shape and colour to 
the cephalics, with white knob-shaped sense organ at the base (Fig. 25); snout long, dark-brown, with a whitish line before the tentaculated margin of the mouth and two gray lappets with white dots; of the same dark colour are washed the uppermost side of the eyes, the forehead and the neck, where a "V" shaped draw is painted; both neck lobes not digitated, gray with white stains; the glandular area under operculum forms a horseshoe draw (Fig. 24).

DisTRIBUTION. The species was originally reported as endemic to the Strait of Messina, as well as in the following papers and single citations. Materials here studied allowed us to enlarge this area to other two more Southern localities: Giardini Naxos, in the same territory of Messina, and Riposto, which is comprised in the northern territory of Catania, $60 \mathrm{~km}$ South to the type locality (Fig. 1).

\section{DISCUSSION}

The exam of the diagnostic morphological characters of $J$. seguenzae do not leave any doubt in considering it as a good separated species from the other congeners, especially from those of the $J$. striatus group, which are morphologically related.

Notwithstanding the doubts expressed by Cretella (1993) on the correct first institution of the taxon (“... Ghisotti \& Melone ..., who designate it, however, as a form connectible to J. striatus"), we think that the AA., although briefly, wanted to describe a real new species, only similar to J. striatus. Numerous new species of the "J. striatus group" were described in recent times, but are morphologically different from J. seguenzae and seem confined to other restricted geographical areas. Moreover, a possible relation of J. seguenzae with J. striatus delpreteanus, a controversial taxon typical of the Faro lake, northern to Messina (Fig. 14), whose taxonomical position is still debated, is excluded after comparisons to topotypical specimens. This latter, in fact, is characterized by a shell almost thin with inflated whorls and sculpture of numerous and almost smooth spiral chords alternated with rough interspaces.

Instead, J. seguenzae shows more affinities to what is here considered the true J. striatus (Fig. 12), on account of original pictures and photographs of the type material (The Linnean Collections, Trochus striatus), and to what is here called J. depictus (Fig.
13), whose taxonomical definition needs further and appropriate studies, but which we consider different from the nominal species on account of differences observed in protoconch shape and sculpture (Fig. 10), external soft parts (Figs. 17-19) and ecological habits, being the former typical of sea-grass beds and the latter of rocky bottom's algae. In fact, besides a different pattern of the foot and stain drawings on the head, J. striatus (Figs. 20-22) and $J$. depictus (Fig. 17) show different form of the sensory organs at the base of the epipodial tentacles and colour and form of the mouth lappets. But, compared to them, J. seguenzae has a more cyrtoconoid shape, thick abapical cords with tubercles (Fig. 7), different colour pattern of the shell and of the external soft parts and a different protoconch (Figs. 8-9). Another debated taxon of the same complex, $J$. fraterculus (see Scuderi \& Terlizzi, 2012 for instance), has an almost greenish animal (Cecalupo et al., 2008 and pers. obs.) and a shell sculpture and general outline which make it similar to the two preceding species. For the same reasons above underlined, it is well distinguishable from J. seguenzae.

Another morphologically similar species, also present in the same geographical area, is J. tumidulus (Aradas, 1846), which have a more rounded and stouter outline of the shell, sculptured by granulated instead of smooth medial spiral ridges (Fig. 15).

The protoconch with the first tele-whorl is almost flat in J. seguenzae (height/diameter ratio: 0.46 ) (Fig. 8) and not slightly protruding as in $J$. striatus (height/diameter ratio: 0.5) (Fig. 11) and highly protruding as in J. depictus (height/diameter ratio: 0.6) (Fig. 10). Moreover J. seguenzae has only one flattened protoconch whorl, J. striatus 1.3 inclined whorls and J. depictus 1.2 highly inclined whorls. The protoconch sculpture is more faint in $J$. seguenzae and in J. striatus than in J. depictus.

A similar protoconch, together with the peculiar hydrodynamism conditions of the Strait of Messina and the marked preferences for a specific environment - SGCF (coarse sands and fine gravels under the influence of bottom currents) according to Pérès \& Picard (1964) - suggest for J. seguenzae a lower dispersal capability, notwithstanding the geographical distributional area is here enlarged to more southern areas, characterized however by the same biocenotic assemblage.

J. seguenzae lives on marine sea-grass and green algae. The finding of some specimens on a 


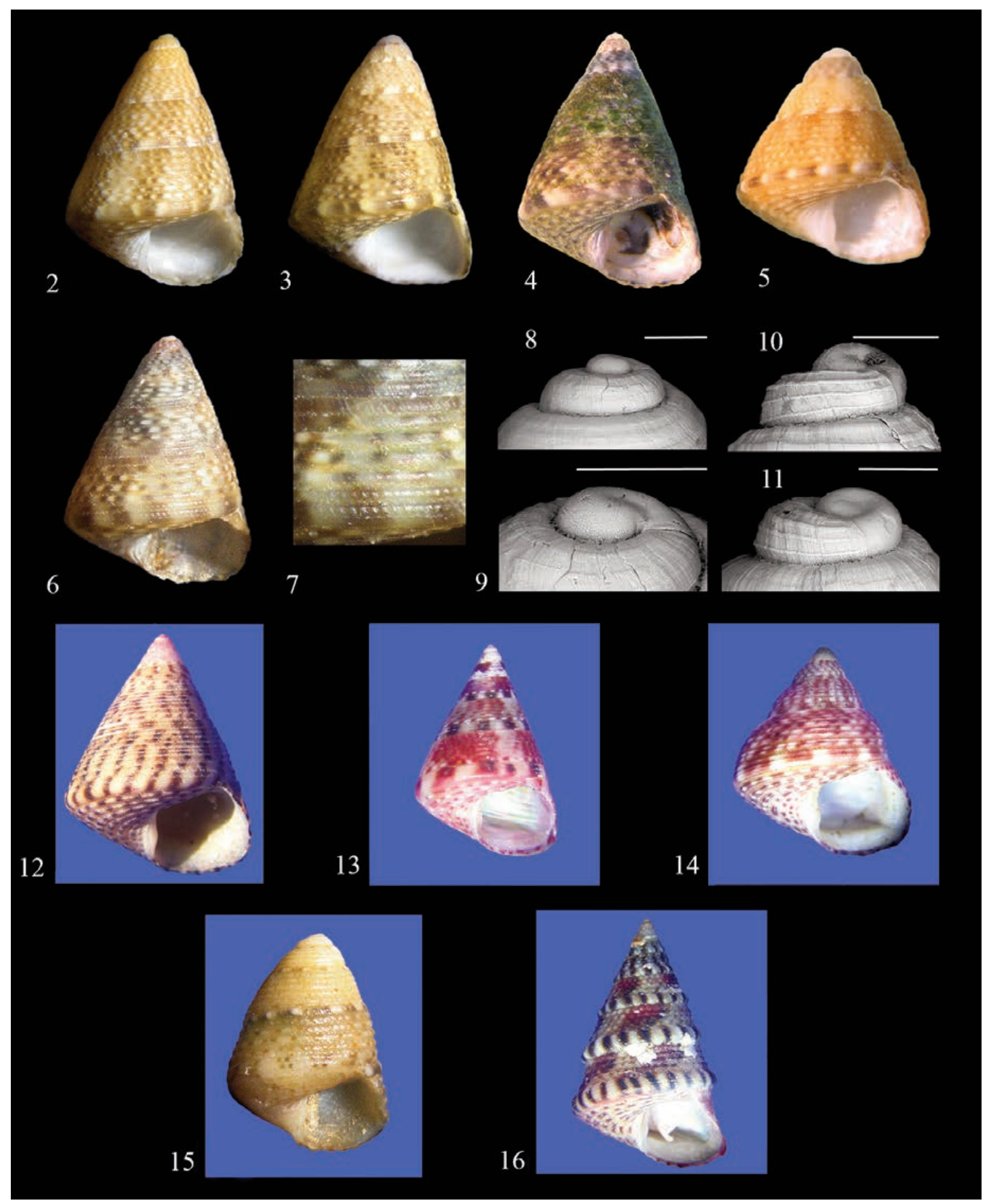

Figures 2-9. Jujubinus seguenzae from Italy. Fig. 2: S. Raineri, "Degassifica" station, Messina, h 5.4 mm. Fig. 3: Ganzirri, Messina, h 5 mm. Fig. 4: Riposto, Catania, live collected, h 6.1 mm. Fig. 5: idem, h 2.4 mm. Fig. 6: Furci Siculo, Messina, h $4.5 \mathrm{~mm}$. Fig. 7: idem, detail of the shell sculpture. Fig. 8: S.E.M. photograph of the protoconch, same data of the specimen in figure 4 (scale bar $200 \mu \mathrm{m}$ ). Fig. 9: S.E.M. photograph of the protoconch, detail of the nucleus, same data of the specimen in figure 4 (scale bar $200 \mu \mathrm{m}$ ). Fig. 10: J. depictus, Catania, S.E.M. photograph of the protoconch (scale bar $200 \mu \mathrm{m})$. Fig. 11: J. striatus, Brucoli, Siracusa, S.E.M. photograph of the protoconch (scale bar $200 \mu \mathrm{m}$ ). Fig. 12: J. striatus, Brucoli, Siracusa, h 10 mm. Fig. 13: J. depictus, Catania, h $5.1 \mathrm{~mm}$. Fig 14: J. striatus delpreteanus, Lago Faro, Messina, h $5.9 \mathrm{~mm}$. Fig.15: J. tumidulus, Ganzirri, Messina, h 3.4 mm. Fig. 16: J. exasperatus, Terrauzza, Siracusa, h $8.0 \mathrm{~mm}$. 


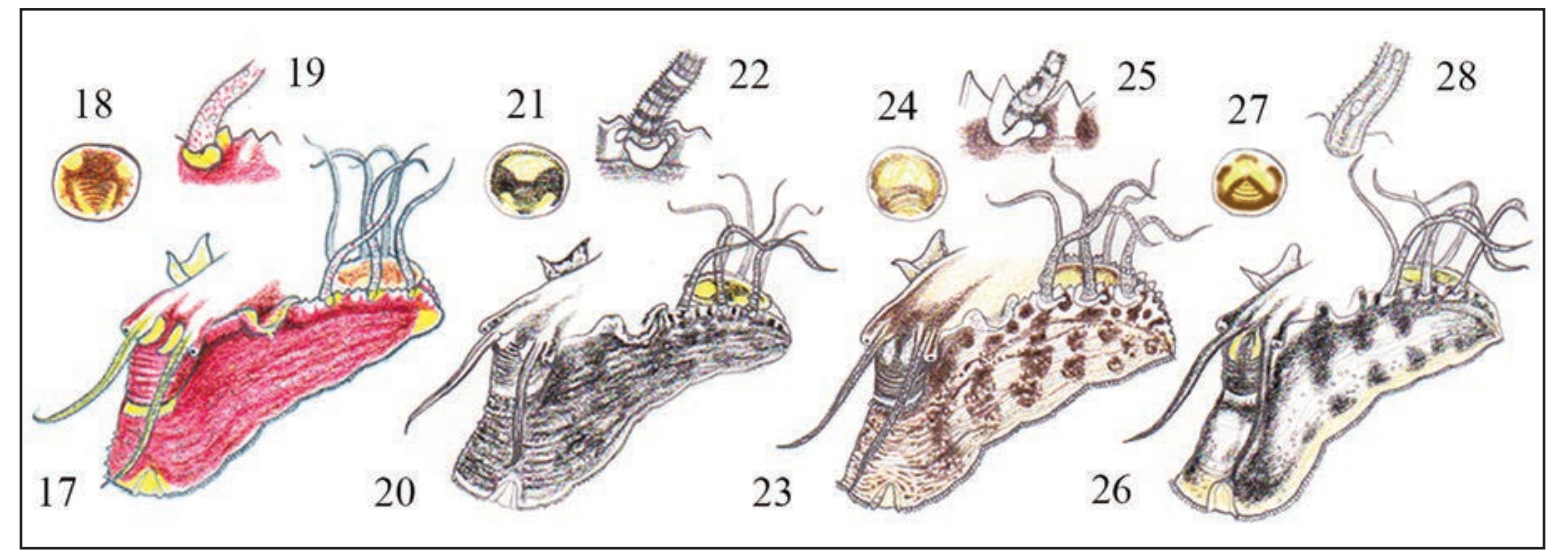

Figures 17-19: Jujubinus depictus, San Giovanni Li Cuti Catania, Italy. Fig. 17: drawing of the external soft parts, San Giovanni Li Cuti Catania, Italy. Fig. 18: detail of the glandular area under operculum; Fig. 19: detail of sense organs of epipodial tentacles. Figures 20-22: J. striatus, Marzamemi, Siracusa, Italy. Fig. 20: drawing of the external soft parts. Fig. 21: detail of the glandular area under operculum; Fig. 22: detail of sense organs of epipodial tentacles. Figures 23-25: J. seguenzae, drawing of the external soft parts of the specimen in figure 4; Fig. 24: detail of the glandular area under operculum; Fig. 25: detail of sense organs of epipodial tentacles. Figure 26: J. exasperatus, drawing of the external soft parts of the specimen in figure 16; Fig. 27: detail of the glandular area under operculum; Fig. 28: detail of sense organs of epipodial tentacles.

floating leaf of Ulva sp. suggests the possibility of the species to disperse in surrounding geographical sites taking advantage of these large-leaf algae transported by the sea currents. It is remarkable, however, that the above described environment is not present far Southern to Riposto, being the characteristics of the bottom influenced by both the lava stones and the sand of the Southern part of the gulf of Catania.

\section{ACKNOWLEDGEMENTS}

We are grateful to prof. Marco Curini-Galletti (Università degli Studi di Sassari, Italy) for his kind availability for literature assistance and interesting suggestions.

\section{REFERENCES}

Cecalupo A., Buzzurro G. \& Mariani M., 2008. Contributo alla conoscenza della malacofauna del Golfo di
Gabes (Tunisia). Quaderni della Civica Stazione Idrobiologica di Milano, pp. 1-175, 92 Tav.

Cretella M., 1993. A review of the living species of the genus Jujubinus Monterosato (Gastropoda: Trochidae). III part. La Conchiglia: International Shell Magazine, 25: 45-50.

Ghisotti F. \& Melone G.C., 1975. Catalogo illustrato delle conchiglie marine del Mediterraneo. Parte 5. Conchiglie, 11 (11-12 supplemento): 147-208.

Oliverio M., 2006. Gastropoda Prosobranchia. In: Revisione della Checklist della fauna marina italiana., available online at http://www.faunaitalia.it/checklist/.

Pérès J.M. \& Picard J., 1964. Noveau manuel de bionomie bentique de la Mer Méditerranée. Recueil des Travaux de la Station marine d'Endoume, 31: 51537.

Scuderi D. \& Terlizzi A., 2012. I molluschi dell'Alto Jonio. Guida teorico-pratica di malacologia mediterranea. Ed. Grifo, Lecce, 108 pp., 41 Tavole.

The Linnean Collections, Trochus striatus, item: P-Z 0010802 Trochus striatus (Shells Linn). http://linneanonline.org/17288/ (last consultation 29/09/2019). 